\title{
Safety of occasional ingestion of gluten in patients with celiac disease: a real-life study
}

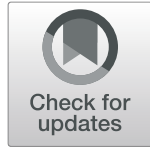

\author{
Luca Elli ${ }^{1 *} \mathbb{D}$, Karla Bascuñán ${ }^{1,2}$, Lorenzo di Lernia ${ }^{3}$, Maria Teresa Bardella ${ }^{1}$, Luisa Doneda ${ }^{4}$, Laura Soldati ${ }^{3}$, \\ Stefania Orlando ${ }^{1}$, Francesca Ferretti ${ }^{1}$, Vincenza Lombardo ${ }^{1}$, Giulio Barigelletti ${ }^{5}$, Alice Scricciolo ${ }^{1}$, Sabrina Fabiano ${ }^{5}$, \\ Maurizio Vecchi ${ }^{1}$ and Leda Roncoroni ${ }^{1,4}$
}

\begin{abstract}
Background: Gluten-free diet (GFD) decreases the quality of life of celiac disease (CD) patients, who frequently ask to occasionally ingest gluten-containing food. We evaluated CD patients reporting voluntary and occasional transgressions to their GFD.

Methods: From October 2017 to September 2018, the patients reporting occasional and voluntary gluten ingestion (GFD-noncompliant) were prospectively enrolled. These patients underwent clinical examination, blood tests, duodenal biopsy, capsule enteroscopy (CE), and a validated food-frequency questionnaire (FFQ) assessing the frequency and quantity of gluten intake. Mortality was calculated and compared to the general population. A group of patients on strict GFD (GFD-adherent) acted as controls.

Results: One thousand three hundred seventy-eight CD patients were evaluated during the study period. One hundred nine $(8 \%)$ reported occasional (weekly or monthly) voluntary ingestion of gluten. The mean gluten intake was $185.2 \pm 336.9 \mathrm{~g} /$ year, and the duration of their incorrect GFD was $8.6 \pm 6.9$ years. Among the noncompliant patients, $57 \%$ did not present any histological alteration; furthermore, the Marsh score profile was not different between compliant and noncompliant patients. Seventy percent did not present any alteration at CE. Seventy-five percent of patients reported no gastrointestinal symptoms after gluten ingestion. Twenty-three percent of patients in the GFD-noncompliant group presented positive tTG-IgA. No association was found between gluten intake, clinical symptoms, and biomarkers. Mortality was not different between the groups and the general population.

Conclusions: Our results are that in a real-life scenario, a group of CD patients on long-term gluten intake showed no significant clinical symptoms or small bowel damage, thus suggesting that a degree of tolerance towards gluten consumption can be reached.
\end{abstract}

Keywords: Celiac disease, Gluten, Gluten-free diet

\section{Background}

Celiac disease (CD) affects approximately $1 \%$ of the population worldwide [1] and is defined as an autoimmune enteropathy triggered by the ingestion of gluten proteins derived from wheat, rye, and barley [2]. CD is characterized by an impaired immune response in genetically susceptible individuals (carrying the HLA DQ2 and/or DQ8 haplotypes) and leads to the inflammation

\footnotetext{
* Correspondence: luca.elli@policlinico.mi.it

${ }^{1}$ Center for Prevention and Diagnosis of Celiac Disease, Gastroenterology and Endoscopy Unit, Department of Pathophysiology and Transplantation, Fondazione IRCCS Ca' Granda Ospedale Maggiore Policlinico, University of Milan, Via F. Sforza 28, 20122 Milan, Italy

Full list of author information is available at the end of the article
}

and atrophy of the small bowel (SB) mucosa [2]. As a consequence, the classical clinical picture of $\mathrm{CD}$ is characterized by nutrient malabsorption with several signs of malnutrition, but extra-intestinal symptoms and association with other autoimmune disorders are frequently present as signs of systemic disease [3, 4].

Nowadays, CD is considered a permanent condition of immunological intolerance to gluten, which requires strict lifelong gluten-free diet (GFD) [3]. The withdrawal of gluten from a patient's diet usually results in the recovery of his/her intestinal mucosa with an improvement of symptoms, SB absorption, and normalization of the circulating autoantibody (anti-type 2 transglutaminase IgA, TG2) [5].

(c) The Author(s). 2020 Open Access This article is distributed under the terms of the Creative Commons Attribution 4.0 International License (http://creativecommons.org/licenses/by/4.0/), which permits unrestricted use, distribution, and reproduction in any medium, provided you give appropriate credit to the original author(s) and the source, provide a link to the Creative Commons license, and indicate if changes were made. The Creative Commons Public Domain Dedication waiver (http://creativecommons.org/publicdomain/zero/1.0/) applies to the data made available in this article, unless otherwise stated. 
It is not clear which of these targets should be considered as the primary or secondary endpoint of GFD for CD patients towards their long-term prognosis [6]. Although safe and efficient, GFD is very restrictive, resulting as a burden on social life and quality of life (for both patients and caregivers) [7-10] and frequently with poor compliance [11-13]. Moreover, the clinical response to inadvertent or voluntary gluten ingestion by treated CD patients can be very heterogeneous, ranging from gastroenteritislike pictures to no symptoms $[3,14]$. Consequently, patients' motivation or understanding in the following strict GFD is often poor. Moreover, it is not known if the prognosis of patients can be made worse by occasional gluten ingestion, especially in patients without symptoms [15].

This issue is crucial in clinical practice for the management of those CD patients that report occasional ingestion of gluten and whose number can reach up to $30 \%$ of cases [16].

Recent data has demonstrated that several CD patients can abandon GFD and maintain a healthy state with no adverse events or $C D$ recurrence [17]. A large group of them will develop intestinal lesions after different exposure periods to gluten consumption, but the fact that some of them seem to tolerate gluten for long periods is intriguing [18]. Thus, the actual role of GFD in the prevention of CD-related complications (e.g., refractory disease, intestinal lymphoma) and other immune disorders is debated $[15,19]$.

The present work aimed to evaluate the dietary, clinical, endoscopic, and histological characteristics of patients with $\mathrm{CD}$ reporting occasional and voluntary transgression to GFD.

\section{Methods}

\section{Patients}

A prospective study was carried out from October 2017 to September 2018 at the "Center for Prevention and Diagnosis of Celiac Disease", Fondazione IRCCS Ca' Granda Ospedale Maggiore Policlinico in Milan (Italy). $\mathrm{CD}$ diagnosis was made according to the national and international guidelines $[20,21]$ including positivity to anti-type 2 transglutaminase IgA (TG2) and the presence of villous atrophy at duodenal histology, according to the Marsh-Oberhuber classification [22]. All the subjects referring to the outpatient service were clinically evaluated by an expert gastroenterologist, and they were interviewed by a trained nutritionist who evaluated the adherence of the patients to their GFD. Adherence to the GFD was evaluated by means of an in-depth interview executed by a nutritionist trained in the treatment and follow-up of patients affected by gluten-related disorders [23].

The patients were discriminated on the basis of the voluntary ingestion of gluten-containing food types. The kind of symptoms (bowel habits, abdominal pain, dyspepsia, meteorism, diarrhea, asthenia, constipation, gastro-esophageal reflux, etc.) arising after gluten ingestion was reported, when present. CD patients underwent upper endoscopy with duodenal biopsies. During gastroscopy (Pentax, EG27-i10 gastroscope), at least 4 oriented biopsies from the distal duodenum and 2 from the bulb were taken using standard endoscopic forceps (Boston Scientific, Radial Jaw ${ }^{\mathrm{Ts}} 4$ ) and were routinely processed for hematoxylin-eosin and CD3 staining as previously described [24]. All the obtained biopsies were reviewed by a pathologist and classified according to the Marsh-Oberhuber criteria [22]. Further, capsule enteroscopy (CE) was carried out after SB cleaning the day before the procedures with $2 \mathrm{~L}$ polyethylene glycol and overnight fasting. An axial view capsule system (Pillcam SB3, Medtronic) was used. At the end of the examination, the data recorded from the capsules were acquired. The recorder was removed after $12 \mathrm{~h}$ and the data downloaded to the dedicated system. CEs were read by an expert physician reading more than 100 CEs per year [25]. A suspicion of mucosal atrophy was posed in the presence of mosaicism, scalloping, granular mucosa, and/or loss of SB folds.

The histological and serological data from a randomly selected fully GFD-compliant, TG2 IgA-negative group of $C D$ patients examined over the same period of time were used as control data.

The patients who agreed to participate gave their written informed consent and were enrolled in the study. The local Ethics Committee for Human Research of the City of Milan approved the study protocol (ref. no. 344 2018).

\section{Evaluation of gluten intake}

For the patients reporting voluntary and occasional ingestion of gluten-containing food, the gluten consumption was assessed by means of a frequency food questionnaire (FFQ) validated and modified in the $C D$ population [26]. FFQ was used to evaluate the frequency and the quantity of gluten-containing foods consumed during the last 12 months. A trained nutritionist administered the questionnaire: information on frequency, type of meals, and when gluten was consumed was collected. In addition to specific questions on foods with predefined gluten content, the FFQ also included open questions to detect and include any eventual (sporadic) gluten intake.

To understand the dietary source of gluten and which foods were most frequently consumed, a qualitative analysis of the diet was carried out; foods were grouped into five food categories: (a) bread and substitutes, (b) sweets, (c) beer, (d) pasta and other cereals, and (e) pizza/ focaccia. 
The intake of gluten from each food category was estimated on the basis of conversion factors ( $8.9 \mathrm{~g}$ gluten/ $100 \mathrm{~g}$ wheat flour, $4.2 \mathrm{~g}$ from barley, $3.0 \mathrm{~g}$ from rye, and 1.29 from oats) [27]. When analyzing beer consumption, the gluten content was obtained using a specific conversion factor, $0.00185 \mathrm{mg}$ gluten $/ \mathrm{ml}$ beer [28].

\section{Mortality}

In order to avoid any bias on the mortality rate, death and causes of death were collected from the Central Register of Italy's National Health Service collecting epidemiological data on the whole Italian population. The analysis was carried out on the overall mortality levels for all causes/pathologies. Comparisons were achieved using the mortality tables of Lombardy's population (from Italy's National Institute of Statistics, ISTAT). The SURVSOFT $^{\circledast}$ V.2.0 software was used for the analysis (Cancer Register Bavaria, URL: http://www.krebsregister-bayern.de/software_e.html) [17]. The standardized mortality ratio (SMR) was defined as the ratio of the observed number of deaths in the population being studied and the expected number of deaths in a comparable group of individuals from the general population, matched with respect to the main factors affecting mortality, commonly age, sex, and calendar period.

\section{Statistical analysis}

The data are described as mean \pm SD or median (interquartile range) unless otherwise indicated. The continuous demographic variables were compared between the groups using independent Student's $t$ test. Fisher's exact test was used to evaluate the distribution of categorical variables (i.e., gender distribution, the presence of gastrointestinal symptoms), the Marsh score between the groups of adherence to the GFD. STATA ${ }^{\circ}$ rel. 13.1 (StataCorp, College Station, TX) was used, and statistical significance was set at $5 \% \alpha$ level.

\section{Results}

Among the 1378 adult CD subjects [mean age $48 \pm 16$, mean age at diagnosis $37 \pm 34,344$ (25\%) males] referred to our outpatient service during the study period, 109 (8\%) [mean age $45 \pm 13$, mean age at diagnosis $29 \pm 19$, $38(35 \%)$ males] reported some voluntary and occasional ingestion of gluten-containing food. The number of males was significantly $(p=0.03)$ higher in the group of patients referring to voluntary gluten ingestions. No differences in age or age at diagnosis were observed. Notably, the mortality of patients reporting some voluntary occasional ingestion of gluten was significantly lower when compared to the general population one (SIR 0, 95\% CI 0-0.61).

Among the patients reporting voluntary gluten ingestion, $48(44 \%)$ patients completed a frequency food questionnaire (FFQ) to estimate the amount of gluten ingested per year; 149 patients following a strict GFD composed the control group (their demographic and clinical details are reported in Table 1). The complete study flowchart is provided in Fig. 1. In the GFDnoncompliant group, the mean amount of gluten ingested by patients was $185.2 \pm 336.9 \mathrm{~g} /$ year $(0.5 \pm 0.9 \mathrm{~g} /$ day) for a mean period of $8.6 \pm 6.9$ years. The frequency of voluntary ingestion of gluten by the patients was usually once a week or month (4\% of patients ingested gluten daily, $40 \%$ at least once a week, $35 \%$ on a monthly basis, and $21 \%$ at least once a year). The description of the alimentary sources of gluten in noncompliant patients is shown in Fig. 2. Dietary gluten mainly came from bread and its substitutes and from pizza/focaccia, pasta, and cereals. In the considered food groups, there were no differences in the intake of gluten. Among patients fulfilling the FFQ, 36 (75\%) reported no symptoms after ingestion of gluten-containing food. In the 12 (25\%) patients reporting a symptomatic relapse after voluntary gluten ingestion, the symptoms were change in bowel habits (16\%), abdominal pain (25\%), constipation (8\%), meteorism (16\%), dyspepsia (12\%), asthenia (16\%), and gastro-esophageal reflux (25\%). This "symptomatic" group did not present any correlation in terms of tTGIgA values or histology.

In the GFD-noncompliant, $22.9 \%$ had positive tTG-IgA values (Table 1). In general, 75 (69\%) of noncompliant patients underwent upper endoscopy with duodenal histology; notably, 43 (57\%) presented an unremarkable duodenal histology (Marsh 0); 50 (66\%) presented normal or nonatrophic lesions (i.e., Marsh 0 , 1, or 2), and 25 (33\%) showed signs of atrophy, demonstrating a Marsh profile similar to the patients of the compliant group. Again, when only patients fulfilling the FFQ (35) have been considered, the Marsh score defining the absence of mucosal damage (Marsh 0) was evidenced in 43 (28.8\%) patients in the GFD-adherent vs. 16 (45.7\%) patients in the GFD-noncompliant group $(p=0.55)$. The same comparison for duodenal atrophy (Marsh 3) showed a $28.8 \%$ in the GFD-adherent compared to the $34.3 \%$ in the GFDnoncompliant group. In Fig. 3a, the different grades of villous atrophy are reported; no statistical differences have been found between the compliant and noncompliant groups. Moreover, no statistical differences were found when comparing the gluten intake of GFD-noncompliant patients with or without duodenal histologic damage: the noncompliant patients with Marsh 0 duodenal histology consumed 131.4 \pm 154.4 g/year, Marsh 1-2 $472.7 \pm 707.9$ g/year, and Marsh $3187.9 \pm 206.0$ g/year. More details about the types of gluten-containing food ingested and their relationship to duodenal histology are reported in Fig. 3b. In Fig. 3c and d, two duodenal histologic images are reported. Moreover, there was no association between 
Table 1 Characteristics of enrolled patients

\begin{tabular}{llll}
\hline & GFD-noncompliant $(n=48)$ & GFD-adherent $(n=149)$ & $p$ value \\
\hline Age, years & $45.5 \pm 16.2$ & $43.7 \pm 12.5$ & 0.357 \\
Gender, M/F & $17 / 31$ & $21 / 128$ & 0.001 \\
Age at CD diagnosis, years ${ }^{\dagger}$ & $30(6.5-49.2)$ & $33(25-41)$ & 0.431 \\
Duration of the diet, years & $8.6 \pm 6.9$ & $5.9 \pm 7.6$ & 0.110 \\
Positive anti-transglutaminase antibody, $\%$ & 22.9 & $30(20 \%)$ & 0.000 \\
Presence of autoimmune diseases, $n(\%)$ & $14(29 \%)$ & 0.23 \\
\hline
\end{tabular}

${ }^{\dagger}$ Data as median (interquartile range)

the frequency of gluten intake and intestinal mucosal damage $(p=0.896)$, gastrointestinal symptoms $(p=0.292)$, tTG-IgA positivity $(p=0.346)$, and the extent of the atrophic lesion as reported by CE $(p=0.209)$.

Thirty $(62 \%)$ noncompliant $\mathrm{CD}$ patients underwent $\mathrm{CE}$, and 21 (70\%) turned out unremarkable. In 9 (30\%) cases, endoscopic signs of mucosal atrophy were described at CE. The following endoscopic signs of atrophy have been reported: mosaicism in 3 cases; mosaicism and scalloping in 3; scalloping and granular mucosa in 1; mosaicism, scalloping, and granular mucosa in 1 ; and granular mucosa in 1 case. The extension of SB atrophy expressed as the percentage of the SB transit time was $8.0 \pm 3.2 \%$. Again, the amount of gluten voluntarily ingested by patients with an atrophic mucosa at $C E$ vs. CD patients without atrophy at CE was not statistically different, being $111.5 \pm 159.7$ and $211.9 \pm 188.8 \mathrm{~g}$ gluten per year, respectively. Considering the presence of atrophy at histology as the reference standard (all patients undergoing $\mathrm{CE}$ were histologically evaluated), sensitivity and specificity of CE were 0.6 (95\% CI $0.26-0.88)$ and 0.85 (95\% CI 0.61-0.97), respectively. In Fig. 4a and b, two examples of $\mathrm{CE}$ investigations are represented.

\section{Discussion}

Our study has shown that occasional and voluntary dietary gluten intake is not associated with the onset of clinical, serological, histologic, or endoscopic signs of CD for a group of $\mathrm{CD}$ patients. In particular, no association was found between histological alterations and the amount of gluten intake after $\mathrm{CD}$ diagnosis.

$\mathrm{CD}$ is the most common autoimmune enteropathy in the Western countries, and strict lifelong GFD is considered the only available treatment, usually inducing symptomatic remission, mucosal healing, and normalization of the serological alterations [3]. However, looking at GFD without a "dogmatic" point of view, a number of ambiguities and/or questions arise [15]: what is the prognosis of patients occasionally assuming gluten? What is the value of histology and serology during follow-up? Can some patients develop any tolerance to gluten? What is the role of GFD in asymptomatic patients? As a consequence, the "historical theory" that strict GFD is necessary for all CD patients and, forever, is somehow questionable. Furthermore, GFD usually worsens the quality of life of $\mathrm{CD}$ patients, and thus, a number of patients present a low degree of compliance

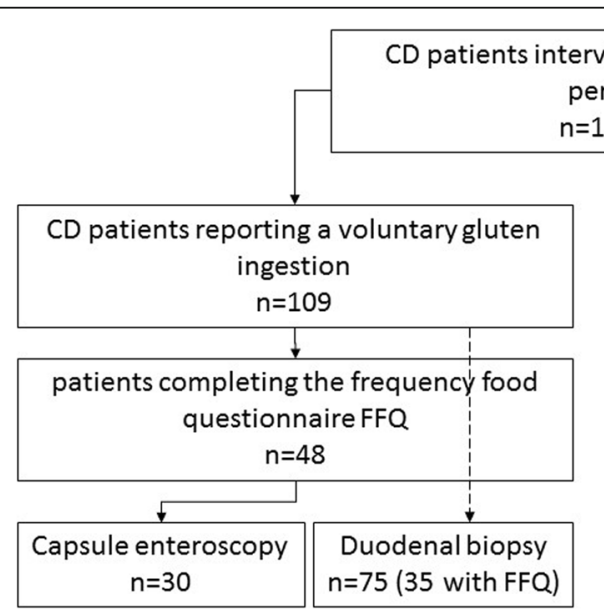

Fig. 1 Flow chart on the patients participating in the study 


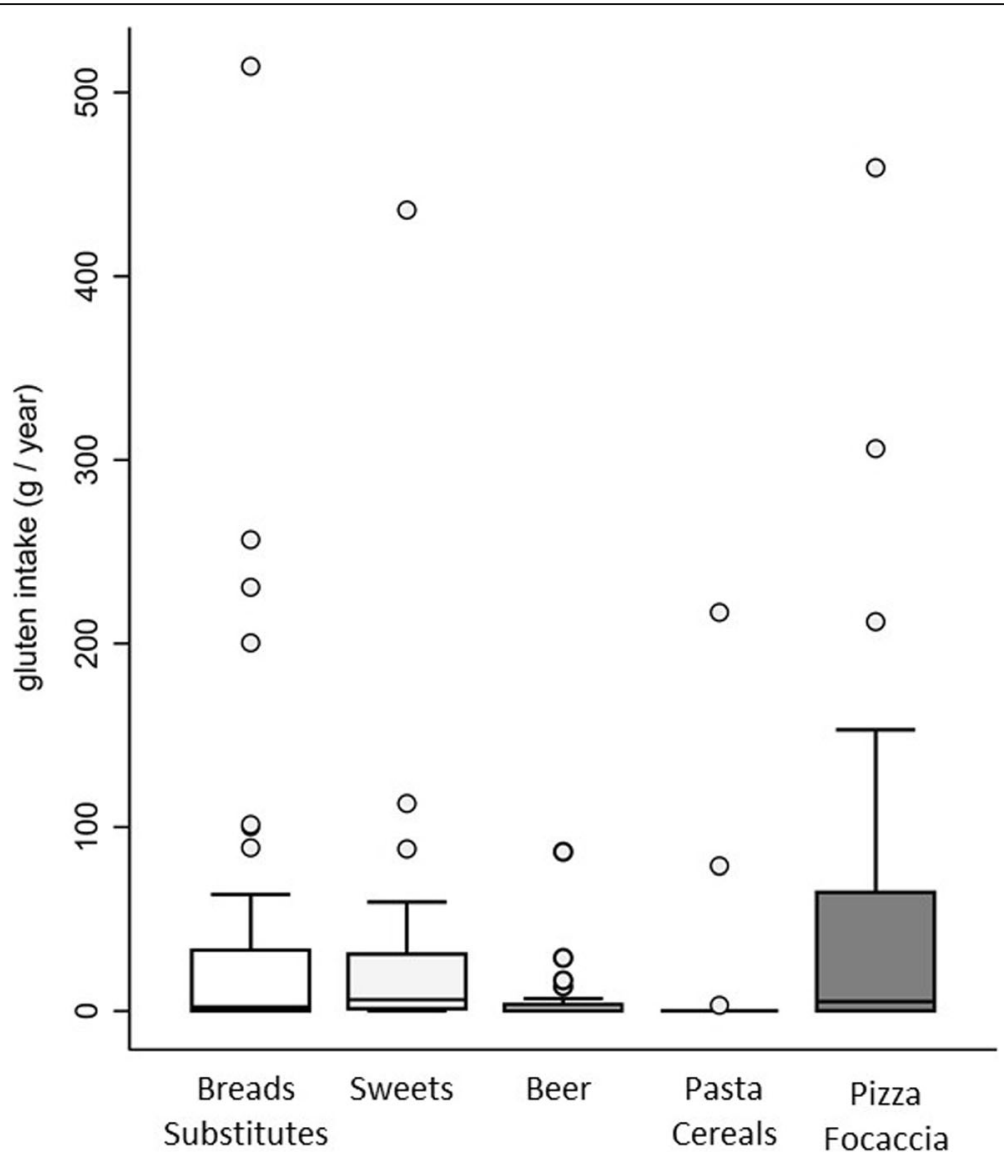

Fig. 2 Gluten intake from the main alimentary groups

to GFD because of their occasional ingestion of gluten, for example, during social events $[5,16]$.

In our cohort of noncompliant CD patients, mainly composed of asymptomatic patients, voluntary gluten ingestion has occurred on a weekly or monthly basis and has been maintained by the patients over a long period of time. During such time, those patients have been followed by our outpatient service on an annual basis through nutritional counseling, gastroenterological visits, and hematological and endoscopic investigations. Notably, the mortality of these patients is not different (if not lower) when compared to the mortality of the general population. The results from the studies to date investigating the mortality risk in $\mathrm{CD}$ patients are conflicting. The major problems in clearly defining such a risk come from the difficulty to distinguish between diagnosed and undiagnosed $\mathrm{CD}$ patients, patients with different $C D$ sub-types, and to extrapolate those patients affected by refractory celiac disease (RCD) from the population database. RCD, although rare (less than $1 \%$ of $C D$ patients), presents a very high risk of malignant transformation and consequently a high mortality rate: the presence of RCD in the analyzed cohorts could represent a bias in studies investigating mortality in $C D$ $[29,30]$. If some studies showed a fourfold increased mortality in CD [31,32], mainly due to lymphoma, without demonstrating a clear connection with gluten exposure, often only indirectly suggested [33], other studies have failed to confirm this scenario [34]. In line with our findings, Olen et al. have analyzed mortality in GFD-compliant and GFD-noncompliant patients without finding any connections to the development of lymphoma [35].

Looking at the duodenal histology (usually considered as the reference standard for CD management) of noncompliant patients compared to the patients following a strict GFD, the incidence of patients maintaining duodenal atrophy was similar in the two groups (roughly $30 \%$ without differences regarding the amount of ingested gluten between the noncompliant patients presenting or not any duodenal damage. It is well known that one third of $\mathrm{CD}$ patients correctly responding to GFD retain some sort of duodenal damage at histology [36]. The clinical significance of this finding is unknown and controversial. For this reason, it is doubtful if the duodenal damage found in noncompliant patients is really induced by gluten ingestion or by chance. 


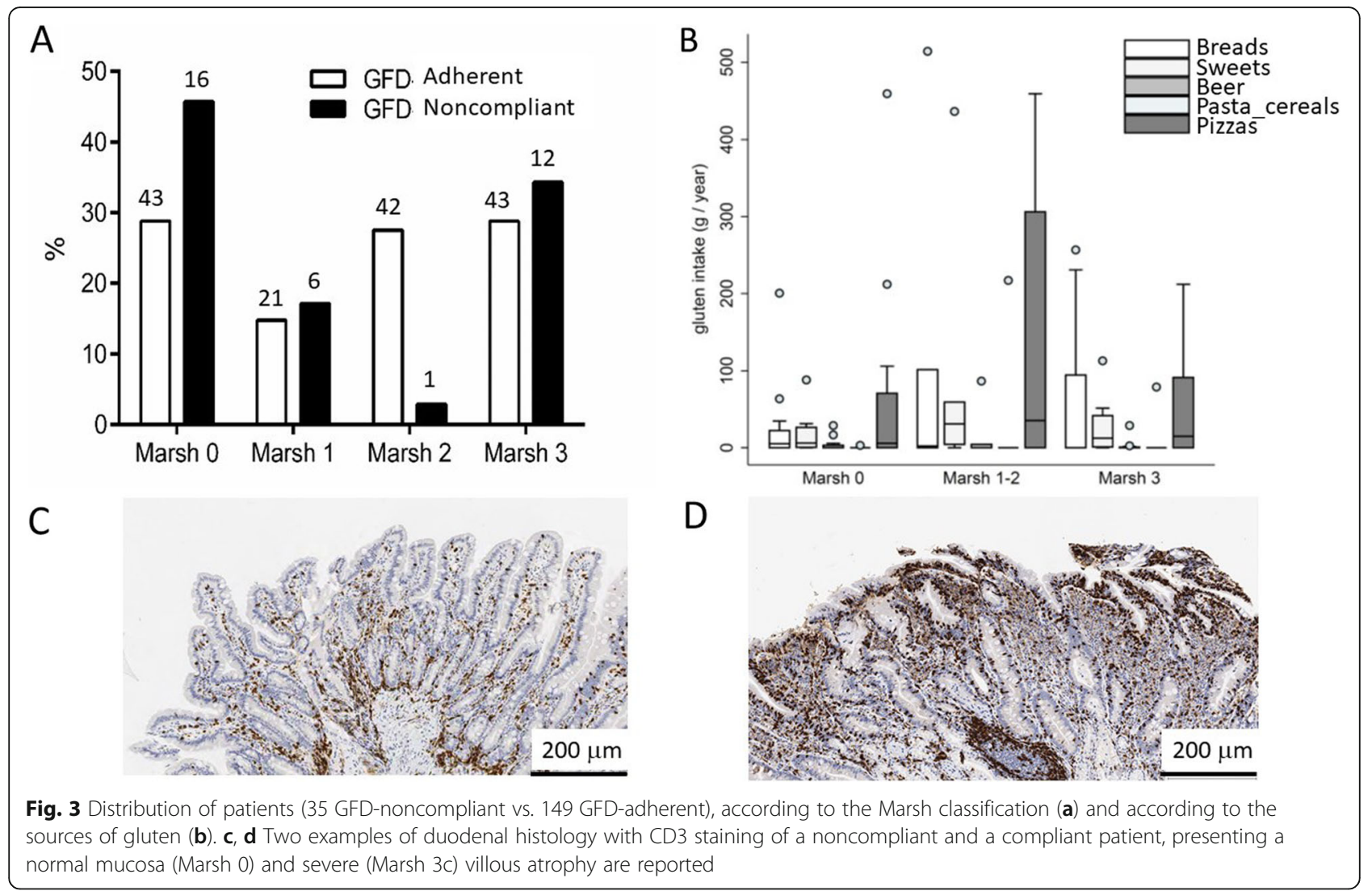

Moreover, in order to investigate the presence of small bowel lesions beyond the Treitz ligament, as indicated by the recent guidelines and meta-analyses [37, 38], CE has been performed without showing any significant alterations but some signs of proximal atrophy in a small part of patients.

In our cohort of noncompliant patients, only the presence of circulating tTGA was significantly increased as compared to compliant controls. However, the tTGA levels do not correlate with the dose of ingested gluten or with the frequency of its ingestion. This finding is in line with earlier studies demonstrating the presence of tTGA in noncompliant patients, especially during childhood. Again, the prognostic significance of such peripheral signs in the absence of symptoms or histologic alterations remains unclear and not correlated to any malignancy development [30].

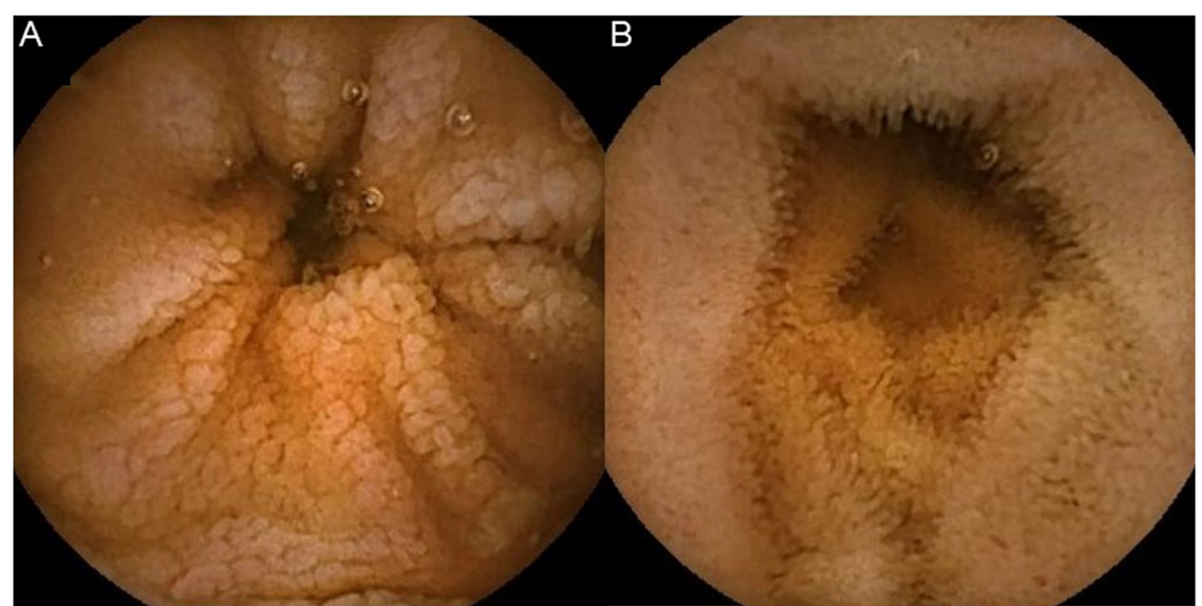

Fig. 4 Capsule endoscopy investigations presenting atrophic (a) and normal (b) mucosa 
There is evidence supporting the hypothesis that it would be possible to achieve a certain level of tolerance to gluten after a variable period depending on each particular patient. In this regard, the systematic reviews available to date have focused on determining what can be considered as the highest safe intake of gluten for $\mathrm{CD}$ patients. Hischenhuber et al. have concluded that the maximum daily intake of gluten should be between 10 and $100 \mathrm{mg}$ [39]. Other authors have reported that this limit is highly variable with some patients tolerating an average of 34-36 $\mathrm{mg}$ of gluten per day. Although there is no evidence to determine a single definitive threshold, a daily gluten intake of $<10 \mathrm{mg}$ is unlikely to cause significant histological abnormalities in these patients [40]. This daily limit can represent an apparent individual tolerance level. It has been supposed that tolerance to gluten can be related to the age at $\mathrm{CD}$ diagnosis: individuals with diagnosis during childhood could develop a greater degree of tolerance compared to diagnosis at adulthood [41]. Other reports have demonstrated that some adult patients diagnosed during childhood did not show clinical or histological relapse after initially consuming dietary gluten $[42,43]$. It should be mentioned that these studies came with methodological considerations mainly related to the evaluation of serology and histology of duodenal biopsies but not focusing on what could be the predictive factors of gluten tolerance. Notably, the studies investigating gluten tolerance or performing a gluten challenge administered gluten on a daily basis while the majority of patients in our study and in real life ingested gluten sporadically or only during specific events. This consideration suggests that it is the timing of the assumption (chronic vs. sporadic) more than the quantity of gluten that can drive a significant immunological and histological response.

Although our study involved a large number of patients followed over a long time period, it presents some points of weakness such as the absence of a randomized challenge with occasional gluten ingestion and the mono-centric design. Furthermore, we did not perform complete evaluations of comorbidities, apart from the presence of autoimmune diseases that appeared not related to gluten ingestion. This finding is in line with a previously published study analyzing the risk factors for the development of autoimmunity in CD [4].

\section{Conclusions}

In summary, our study has shown that a group of celiac patients with long-term gluten intake shows no significant clinical symptoms or histological abnormalities, suggesting that a degree of tolerance towards gluten consumption can be reached. A better understanding of the mechanisms through which some patients can reach a degree of tolerance to gluten could indeed result in personalized GFD allowing for the intake of different amounts of gluten. This achievement can help to improve a patient's quality of life and diminish the social burden associated with lifelong GFD.

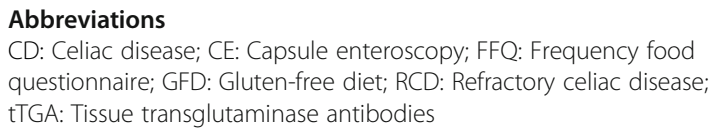

\section{Acknowledgements}

We thank Marcello Hinxman-Allegri for the English language revision and editing of the manuscript. Furthermore, we thank Alessandro del Gobbo for the histological images.

\section{Authors' contributions}

$L E, M T B, M V$, and $L R$ were responsible for planning the study. $L D L, S O, F F, V L$, and $A S$ were responsible for the data acquisition. $K B$, LD, and LS were responsible for the analysis of the data. SF and GB were responsible for the analysis of mortality. All authors approved the final version of the manuscript.

\section{Funding}

This research was funded by Fondazione IRCCS Ca' Granda and through grants from the Italian Ministry of Health and Lombardy's Regional Government Authority (Ministero della Salute and Regione Lombardia, call No. 2011-02348234)

\section{Availability of data and materials \\ The datasets used and/or analyzed during the current study are available from the corresponding author on reasonable request.}

\section{Ethics approval and consent to participate}

The local Ethics Committee for Human Research of the City of Milan approved the study protocol (ref. no. 344_2018). Enrolled patients gave their written consent to participate in the study. The study adhered to the Declarations of Helsinki.

\section{Consent for publication}

Not applicable

\section{Competing interests}

The authors declare that they have no competing interests.

\section{Author details}

${ }^{1}$ Center for Prevention and Diagnosis of Celiac Disease, Gastroenterology and Endoscopy Unit, Department of Pathophysiology and Transplantation, Fondazione IRCCS Ca' Granda Ospedale Maggiore Policlinico, University of Milan, Via F. Sforza 28, 20122 Milan, Italy. ${ }^{2}$ Department of Nutrition, School of Medicine, University of Chile, Santiago, Chile. ${ }^{3}$ Department of Health

Sciences, University of Milan, Milan, Italy. ${ }^{4}$ Department of Biomedical, Surgical and Dental Sciences, University of Milan, Milan, Italy. ${ }^{5}$ Cancer Registry Unit, Fondazione IRCCS Istituto Nazionale dei Tumori, Milan, Italy.

Received: 11 November 2019 Accepted: 5 February 2020

Published online: 16 March 2020

\section{References}

1. Ludvigsson JF, Murray JA. Epidemiology of celiac disease. Gastroenterol Clin N Am. 2019;48(1):1-18

2. Schuppan D, Junker $Y$, Barisani D. Celiac disease: from pathogenesis to novel therapies. Gastroenterology. 2009;137(6):1912-33.

3. Elli L, Ferretti F, Orlando S, Vecchi M, Monguzzi E, Roncoroni L, Schuppan D. Management of celiac disease in daily clinical practice. Eur J Intern Med. 2019;61:15-24. https://doi.org/10.1016/j.ejim.2018.11.012. Epub 2018 Dec 5. PMID: 30528262

4. Elli L, Bonura A, Garavaglia D, Rulli E, Floriani I, Tagliabue G, Contiero P, Bardella MT. Immunological comorbity in coeliac disease: associations, risk factors and clinical implications. J Clin Immunol. 2012;32(5):984-90.

5. Bascuñán KA, Vespa MC, Araya M. Celiac disease: understanding the glutenfree diet. Eur J Nutr. 2017;56(2):449-59. 
6. Lee SK, Lo W, Memeo L, Rotterdam H, Green PH. Duodenal histology in patients with celiac disease after treatment with a gluten-free diet. Gastrointest Endosc. 2003;57(2):187-91.

7. Ferretti F, Branchi F, Dell'Osso B, Conte D, Elli L. Coping with celiac disease: how heavy is the burden for caregivers? Rev Esp Enferm Dig. 2017;109(4): 250-5.

8. Nachman F, Mauriño E, Vázquez H, Sfoggia C, Gonzalez A, Gonzalez V, Plancer del Campo M, Smecuol E, Niveloni S, Sugai E, et al. Quality of life in celiac disease patients: prospective analysis on the importance of clinical severity at diagnosis and the impact of treatment. Dig Liver Dis. 2009;41(1): $15-25$.

9. Lerner A, Matthias T. Gluten free diet- tough alley in torrid time. Int J Celiac Dis. 2017;5(2):50-5

10. Lerner A, O'Bryan T, Matthias T. Navigating the gluten-free boom: the dark side of gluten free diet. Front Pediatr. 2019;7:414.

11. Silvester $J A$, Weiten $D$, Graff $L A$, Walker JR, Duerksen DR. Living gluten-free: adherence, knowledge, lifestyle adaptations and feelings towards a glutenfree diet. J Hum Nutr Diet. 2016;29(3):374-82.

12. Norsa L, Tomba C, Agostoni C, Branchi F, Bardella MT, Roncoroni L, Conte D, Elli L. Gluten-free diet or alternative therapy: a survey on what parents of celiac children want. Int J Food Sci Nutr. 2015;66(5):590-4.

13. Branchi F, Tomba C, Ferretti F, Norsa L, Roncoroni L, Bardella MT, Conte D, Elli L. Celiac disease and drug-based therapies: inquiry into patients demands. Digestion. 2016;93(2):160-6.

14. Bardella MT, Elli L, Velio P, Fredella C, Prampolini L, Cesana B. Silent celiac disease is frequent in the siblings of newly diagnosed celiac patients. Digestion. 2007;75(4):182-7.

15. Itzlinger A, Branchi F, Elli L, Schumann M. Gluten-Free Diet in Celiac. Disease-Forever and for All? Nutrients. 2018;10(11):1796. https://doi.org/10. 3390/nu10111796. PMID: 30453686; PMCID: PMC6267495.

16. Freeman HJ. Dietary compliance in celiac disease. World J Gastroenterol. 2017;23(15):2635-9.

17. Norsa L, Branchi F, Bravo M, Ferretti F, Roncoroni L, Somalvico F, Conte D, Bardella MT, Fabiano S, Barigelletti G, et al. Celiac disease 30 years after diagnosis: struggling with gluten-free adherence or gaining gluten tolerance? J Pediatr Gastroenterol Nutr. 2018:67(3):361-6.

18. Schmitz J. Is celiac disease a lifelong disorder? Clin Invest Med. 1996;19(5):352-6.

19. Elli L, Discepolo V, Bardella MT, Guandalini S. Does gluten intake influence the development of celiac disease-associated complications? J Clin Gastroenterol. 2014:48(1):13-20.

20. Elli L, Villalta D, Roncoroni L, Barisani D, Ferrero S, Pellegrini N, Bardella MT, Valiante F, Tomba C, Carroccio A, et al. Nomenclature and diagnosis of gluten-related disorders: a position statement by the Italian Association of Hospital Gastroenterologists and Endoscopists (AIGO). Dig Liver Dis. 2017; 49(2):138-46.

21. Ludvigsson JF, Bai JC, Biagi F, Card TR, Ciacci C, Ciclitira PJ, Green PH, Hadjivassiliou M, Holdoway A, van Heel DA, et al. Diagnosis and management of adult coeliac disease: guidelines from the British Society of Gastroenterology. Gut. 2014;63(8):1210-28.

22. Oberhuber $\mathrm{G}$, Granditsch $\mathrm{G}$, Vogelsang $\mathrm{H}$. The histopathology of coeliac disease: time for a standardized report scheme for pathologists. Eur J Gastroenterol Hepatol. 1999;11(10):1185-94.

23. Rubio-Tapia A, Hill ID, Kelly CP, Calderwood AH, Murray JA, Gastroenterology ACo. ACG clinical guidelines: diagnosis and management of celiac disease. Am J Gastroenterol. 2013;108(5):656-76 quiz 677.

24. Elli L, Zini E, Tomba C, Bardella MT, Bosari S, Conte D, Runza L, Roncoroni L, Ferrero S. Histological evaluation of duodenal biopsies from coeliac patients: the need for different grading criteria during follow-up. BMC Gastroenterol. 2015;15:133.

25. Tomba C, Elli L, Bardella MT, Soncini M, Contiero P, Roncoroni L, Locatelli M, Conte D. Enteroscopy for the early detection of small bowel tumours in atrisk celiac patients. Dig Liver Dis. 2014;46(5):400-4.

26. Mazzeo T, Roncoroni L, Lombardo V, Tomba C, Elli L, Sieri S, Grioni S, Bardella MT, Agostoni C, Doneda L, et al. Evaluation of a modified Italian European prospective investigation into cancer and nutrition food frequency questionnaire for individuals with celiac disease. J Acad Nutr Diet. 2016;116(11):1810-6

27. Schalk K, Lexhaller B, Koehler P, Scherf KA. Isolation and characterization of gluten protein types from wheat, rye, barley and oats for use as reference materials. PLoS One. 2017:12(2):e0172819.
28. Panda R, Boyer M, Garber EAE. A multiplex competitive ELISA for the detection and characterization of gluten in fermented-hydrolyzed foods. Anal Bioanal Chem. 2017;409(30):6959-73.

29. Malamut G, Cellier C. Refractory celiac disease: epidemiology and clinical manifestations. Dig Dis. 2015;33(2):221-6.

30. Ludvigsson JF, Montgomery SM, Ekbom A, Brandt L, Granath F. Smallintestinal histopathology and mortality risk in celiac disease. JAMA. 2009; 302(11):1171-8.

31. Rubio-Tapia A, Kyle RA, Kaplan EL, Johnson DR, Page W, Erdtmann F, Brantner TL, Kim WR, Phelps TK, Lahr BD, et al. Increased prevalence and mortality in undiagnosed celiac disease. Gastroenterology. 2009;137(1):88-93.

32. Metzger MH, Heier M, Mäki M, Bravi E, Schneider A, Löwel H, Illig T, Schuppan D, Wichmann HE. Mortality excess in individuals with elevated IgA anti-transglutaminase antibodies: the KORA/MONICA Augsburg cohort study 1989-1998. Eur J Epidemiol. 2006;21(5):359-65.

33. Biagi F, Corazza GR. Mortality in celiac disease. Nat Rev Gastroenterol Hepatol. 2010;7(3):158-62.

34. Lohi S, Mäki M, Rissanen H, Knekt P, Reunanen A, Kaukinen K. Prognosis of unrecognized coeliac disease as regards mortality: a population-based cohort study. Ann Med. 2009;41(7):508-15.

35. Olén O, Askling J, Ludvigsson JF, Hildebrand H, Ekbom A, Smedby KE. Coeliac disease characteristics, compliance to a gluten free diet and risk of lymphoma by subtype. Dig Liver Dis. 2011;43(11):862-8.

36. Lanzini A, Lanzarotto F, Villanacci V, Mora A, Bertolazzi S, Turini D, Carella G, Malagoli A, Ferrante G, Cesana BM, et al. Complete recovery of intestinal mucosa occurs very rarely in adult coeliac patients despite adherence to gluten-free diet. Aliment Pharmacol Ther. 2009;29(12):1299-308.

37. Pennazio M, Spada C, Eliakim R, Keuchel M, May A, Mulder CJ, Rondonotti E, Adler SN, Albert J, Baltes P, et al. Small-bowel capsule endoscopy and device-assisted enteroscopy for diagnosis and treatment of small-bowel disorders: European Society of Gastrointestinal Endoscopy (ESGE) clinical guideline. Endoscopy. 2015;47(4):352-76.

38. Elli L, Casazza G, Locatelli M, Branchi F, Ferretti F, Conte D, Fraquelli M. Use of enteroscopy for the detection of malignant and premalignant lesions of the small bowel in complicated celiac disease: a meta-analysis. Gastrointest Endosc. 2017;86(2):264-273.e261.

39. Hischenhuber C, Crevel R, Jarry B, Mäki M, Moneret-Vautrin DA, Romano A, Troncone R, Ward R. Review article: safe amounts of gluten for patients with wheat allergy or coeliac disease. Aliment Pharmacol Ther. 2006;23(5):559-75.

40. Akobeng AK, Thomas AG. Systematic review: tolerable amount of gluten for people with coeliac disease. Aliment Pharmacol Ther. 2008;27(11):1044-52.

41. Matysiak-Budnik T, Malamut G, de Serre NP, Grosdidier E, Seguier S, Brousse N, Caillat-Zucman S, Cerf-Bensussan N, Schmitz J, Cellier C. Long-term follow-up of 61 coeliac patients diagnosed in childhood: evolution toward latency is possible on a normal diet. Gut. 2007;56(10):1379-86.

42. Shmerling DH, Franckx J. Childhood celiac disease: a long-term analysis of relapses in 91 patients. J Pediatr Gastroenterol Nutr. 1986;5(4):565-9.

43. Mäki M, Lähdeaho ML, Hällström O, Viander M, Visakorpi JK. Postpubertal gluten challenge in coeliac disease. Arch Dis Child. 1989;64(11):1604-7.

\section{Publisher's Note}

Springer Nature remains neutral with regard to jurisdictional claims in published maps and institutional affiliations.

Ready to submit your research? Choose BMC and benefit from

- fast, convenient online submission

- thorough peer review by experienced researchers in your field

- rapid publication on acceptance

- support for research data, including large and complex data types

- gold Open Access which fosters wider collaboration and increased citations

- maximum visibility for your research: over $100 \mathrm{M}$ website views per year

At $\mathrm{BMC}$, research is always in progress.

Learn more biomedcentral.com/submission 